\title{
o Promotor de Saúde 4
}

Ricardo C. Cavalcanti ${ }^{1}$

Pode parecer estranho que eu comece este texto fazendo algumas considerações sobre a relatividade temporal dos fatos históricos; procurando confrontar o passado com o presente, buscando na história passada da humanidade a explicação e as coincidências de sua história presente.

A história não é uma recordação de coisas mortas e estáticas. Ela tem algo de vivo e dinâmico porque a humanidade, a despeito das diferenças culturais e das revoluções tecnológicas, continua a ser basicamente a mesma, com suas fraquezas a grandezas.

O estudioso da história pode observar que, muitas vezes, o passado chega a derrotar a criatividade do presente, e a humanidade é surpreendida reescrevendo uma mesma página que, de alguma forma, já foi vivenciada em outras épocas.

Permitam-me provar isto. Como a ciência já demonstrou que a noção de tempo é relativa, vamos todos voltar para a Europa do ano de 1493, dando um pulinho para trás de, aproximadamente, 500 anos. O Brasil ainda não existia. Ele estava gestando no ventre de suas intocadas florestas. A América tinha sido descoberta há pouco tempo e Colombo acabara de chegar ao Velho Continente para levar as boas novas aos reis da Espanha. É claro que a notícia logo se propagou por toda a Europa, despertando, aqui e ali, admiração, inveja e despeito.

Na corte da França, Carlos VIII, cujo país não tinha a vocação marítima da Península Ibérica, começava a ter sonhos de conquista. 
Afinal ele não se contentava em ficar em segundo plano. Olhando para o mapa da Europa, ele facilmente pôde ver que, ao sul da França, vários pequenos reinos podiam ser conquistados. Entre eles, um dos mais desejáveis era o reino de Nápoles. A Itália ainda não madrugara como nação, de modo que o rei da França, com seu poderoso exército, facilmente invadiu Nápoles e a anexou ao território francês.

O que Carlos VIII não esperava é que, sendo Fernando II, rei de Nápoles, um dos príncipes de Aragão, a Espanha tomasse as dores napolitanas e declarasse guerra à França. Uma guerra que durou de 1495 a 1498, sendo Carlos VIII derrotado e obrigado a entregar 0 reino de Nápoles a Fernando II.

Que tem este episódio, perdido nos livros empoeirados do tempo, com a humanidade atual? De que maneira ele se projeta do passado para reescrever a história do presente?

Esta guerra, que em si teve importância tão secundária que alguns livros didáticos sequer a menciona, se revestiu porém de um valor extraordinário. Não tanto pela campanha das tropas francesas ou pela rivalidade dos reis. Sua importância se evidencia porque, durante o deslocamento das tropas da França, se difundiu uma vasta epidemia do que então foi chamado de morbus gallicus. Nenhuma região da Europa foi poupada. A doença, hoje conhecida como sífilis, seguramente não nasceu durante esta época. Ela estava viva nos bastidores, dormindo sobre forma endêmica, aparecendo aqui a ali, fermentando, para de um salto pular para o palco da história e escrever seu drama ruidoso e letal.

É interessante notar que a tendência das nações mais poderosas é sempre considerar os povos mais incultos, mais fracos, mais pobres, menos avançados dos progressos tecnológicos como sendo responsáveis pelas calamidades da humanidade. Ninguém quer assumir a responsabilidade de coisas desagradáveis. Nem pessoas nem nações. Não foi de admirar, portanto, que o mal-gálico ou francês, fosse considerado mal-napolitano, mal-germânico, mal-polaco. Contudo, franceses, napolitanos, alemães, poloneses a turcos, europeus em geral, logo deixaram de lado as acusações recíprocas. Havia um bode expiatório melhor. Eles passaram a afirmar que a doença não nascera na Europa, mas nas caravelas de Colombo. Os marinheiros tinham contraído a enfermidade dos nativos do Novo Mundo, os quais (que bela concessão à espécie humana) foram contaminados pelos macacos americanos. Uma maravilhosa solução... Afinal macaco não fala, a povos tão pouco importantes não têm voz no concerto das nações. A civilizada Europa poderia dormir de consciência tranqüila. 
Miserável calúnia. O Novo Mundo em nada tinha concorrido para a epidemia gaulesa. Muito ao contrário. Ele é que foi mais tarde contaminado pelo colonizador europeu.

No Brasil, segundo as crônicas da época, a sífilis não existia antes do descobrimento. Somente em 6 de janeiro de 1550 é que 0 Padre Manuel da Nóbrega, em carta escrita de Porto Seguro, nos dá conta de que havia pessoas morrendo do mal-gálico.

É preciso lembrar que, no caso específico da colonização portuguesa, o que nos foi enviado era o que havia de pior em Portugal. Prisioneiros, degradados, criminosos, enfim, a ralé. Mulheres muito poucas, de modo que os lusitanos começaram sua obra colonizando "as vergonhas" de nossas índias. Gilberto Freyre é muito feliz quando afirma que o Brasil "foi sifilizado antes de ser civilizado".

Mal-gálico, português, francês, napolitano, pouco importa a origem, o fato é que a sífilis era uma doença difícil de ser combatida. O mal vinha sorrateiro, encoberto no manto do prazer erótico, vinculado, portanto, a um dos mais maravilhosos e complicados dons da humanidade.

Não faltou ao espírito moralista da época quem considerasse a sífilis "um castigo dos céus", uma prova do que o pecado da carne poderia determinar.

Logo as baterias se assentaram contra os homossexuais e as prostitutas. Eles vendiam amor misturado com sífilis. Não foram poucas as mulheres presas, supliciadas e mortas. Aproveitava-se 0 momento da tragédia para demonstrar que a atividade sexual era basicamente uma característica da natureza animal do homem, apenas suportada com a finalidade procriativa, jamais permitida em busca do prazer.

Não havia remédio contra sífilis. Recordemos que só em 1905 é que Schaudin a Hoffmann descobriram o Treponema pallidum. Cinco anos depois, precisamente em 1910, é que surgiu a arsfenamina, depois a malarioterapia, a quimioterapia e, já nos nossos tempos, a penicilina. Observem, 400 anos sem remédios específicos contra sífilis. A única solução, durante todos estes anos, era combatê-la através de medidas profiláticas. Aconselhava-se a educação sexual; que se procurasse evitar parceiros desconhecidos e, quando isto não fosse possível, que usassem a "camisa de vênus", que nos primeiros tempos era fabricada de linho.

A psicologia do sifilítico era regida pela vergonha, o sentimento de culpa, a tentativa de esconder sua enfermidade. Afinal vivia-se uma época de sifilofobia. Fugia-se do sifilítico, discriminava se 0 sifilítico, abandonava-se o sifilítico. 
Na época, os hábitos sexuais mudaram de alguma forma, mas, passada a fase inicial, superado o grande susto, a humanidade irresponsável continuava a arriscar a pele em busca do prazer erótico. As prostitutas e os homossexuais continuaram a existir, porque eles não pertencem a uma época ou a uma civilização. A propaganda do condom e sua divulgação não tardou a encontrar a resistência daqueles que não se conformavam em vestir aquele paletó peniano de linho toda vez que tivesse de ficar nu para ter relações sexuais. "Isto é ridículo", diziam eles. O que, pensando bem, talvez tivessem razão... (Imaginem mentalmente o quadro).

Voltemos agora para o hoje, quase à beira de um novo milênio, 496 anos depois. Permitam-me relembrar o que foi dito no início deste texto. Os tempos mudaram, mas algo essencial da história volta a se repetir. Agora o real é a AIDS, que veio da África para a América, dos negros que se contaminaram com macacos africanos, destes para os homossexuais e, finalmente, para a população branca dos Estados Unidos e do mundo.

Neste tempo de aidofobia, quem foi contaminado se cobre de vergonha, de sentimentos de culpa, procurando esconder a doença dos amigos e dos vizinhos. Foge-se do aidético, discrimina-se 0 aidético. Afinal, contra a AIDS não há remédios a não ser fazer a profilaxia da doença através da educação sexual e do uso da camisa de vênus, nesta altura, substituído o linho e a bexiga de animais pela tecnologia da vulcanização.

Também houve uma fase de perseguição contra homossexuais e prostitutas, quando moralistas se aproveitaram para fazer apologia contra a sexualidade. Também nos primeiros momentos, houve mudanças nos hábitos sexuais. Agora, o comércio das prostitutas e a atividade, geralmente anônima e clandestina, dos homossexuais continua, a todo vapor, sua existência tortuosa.

Muita gente não usa o condom, embora ele tenha sido largamente difundido pela propaganda dos meios de comunicação de massa. $\mathrm{O}$ não-use é racionalizado dizendo-se que a camisinha "tira a sensibilidade", "interrompe o ato sexual no melhor da festa", além de ser "coisa antinatural".

Estou certo que muitos morrerão, mas, um dia, a humanidade acabará por vencer a AIDS, e Deus queira que seja em futuro bem próximo.

Mas, fiquem certos os historiadores que viverão nos próximos anos de que a história continuará a dar lições de extraordinária vitalidade e de repetição. Um dia, nova doença sexual vai surgir, povos mais pobres ou segmentos minoritários da sociedade serão culpados de sua difusão, e que se cuidem os macacos do futuro, porque eles 
serão responsabilizados. É interessante como, na sua renovação, a humanidade se repete.

É claro que eu não sei o que vai ocorrer daqui a quinhentos anos, mas sei o que ocorreu há cinco séculos, e sei que estamos vivenciando hoje uma monotonia de repetição.

O que é de admirar, o que é de assombrar nestes quinhentos anos, que permeiam entre a sífilis e a AIDS, é que a humanidade não tenha se alertado de que é preciso fazer alguma coisa além de acusar prostitutas e homossexuais ou mudar a tecnologia da fabricação de camisa de vênus. Em quinhentos anos não se avançou um passo sequer naquilo que realmente é fundamental: conscientizar o homem do uso adequado de sua sexualidade. Muito ao contrário, nestes momentos trágicos da história humana, o sexo é visto como um veiculador da morte, quando basicamente ele deveria ser reconhecido como um veiculador da vida.

Na história sexual da humanidade pode-se assinalar duas polaridades distintas: períodos de repressão sexual e períodos de extrema liberalidade sexual; tempos sexofóbicos e tempos sexólatras. Distingue-se, claramente, visões culturais diferentes e antagônicas. Mas eu não quero apenas falar sobre revolução sexual, contra-revolução, amor de gregos, troianos, vitorianos, hindus, europeus ou americanos.

Minha proposta é enfatizar a educação sexual, não aquela que é praticada na escola ou no lar, mas aquela que pode e deve ser realizada nos consultórios dos médicos, dos psicólogos, no atendimento prestado pelo pessoal de saúde. Observem que eu falo do "pessoal de saúde" e não daquele profissional que se liniita exclusivamente ao tratamento da doença. Aliás, esta visão do médico como um promotor de saúde é muito mais importante do que aquela que vê no médico um mero curador de doenças.

É extraordinário como os orientais são, neste particular e em muitos outros, bem mais sábios do que nós do Ocidente. A vaidosa e tecnocrática civilização ocidental, muitas vezes, menospreza a sabedoria do Oriente, esquecida de que ela está cristalizada em milhares de anos de pensamento.

Nos povoados do interior da antiga China, era costume que o médico recebesse, da comunidade, uma certa soma mensal de dinheiro ou de alimentos para que ele mantivesse a rigidez da população. Eram assalariados da saúde. Promotores da saúde. Quando alguém adoecia, deixavam de receber dinheiro, porque a doença era considerada um fracasso do médico. Ele vivia da saúde de seus clientes. $\mathrm{O}$ costume ocidental é exatamente o oposto. $\mathrm{O}$ médico vive da doença de seus pacientes. 
Esta digressão é um hino à profilaxia e tem a intenção de reforçar o importante papel pedagógico que o profissional pode desempenhar, no sentido de manter, na sua clientela, a saúde sexual e reprodutiva.

Neste tipo de processo educativo prepara-se o indivíduo para a vida, tornando-o, através do uso responsável e livre de sua sexualidade, um agente promotor da saúde individual e coletiva.

Como o pessoal de saúde pode realizar este objetivo? Naturalmente dois pré-requisitos são imprescindíveis: conhecimento de assuntos sexuais e mudança de atitudes.

Em primeiro lugar é necessário que se tenha uma idéia da sexológia como um todo e isto, infelizmente, não foi oferecido em nossa formação universitária. Eu tenho profundas esperanças de que, um dia, nas faculdades de Medicina e de Psicologia existam disciplinas voltadas à terapia sexual, e que nas faculdades de Enfermagem, de Assistência Social e de Pedagogia, entre as mais importantes, apareça a disciplina de educação sexual. Se isto já tivesse ocorrido, não teríamos de nos defrontar, quase diariamente, com as iatrogenias da área sexual, promovidas por médicos, psicólogos, enfermeiras e educadores. Certamente também poderíamos controlar, com maior facilidade, as chamadas "doenças sexualmente transmissíveis".

Na área específica da ginecologia, estamos cada vez mais pressionados a opinar e tratar de assuntos sexuais. É imprescindível, para a conservação de nosso respeito profissional junto aos clientes, que tenhamos conhecimentos não só dos assuntos reprodutivos, mas também que saibamos nos posicionar no tratamento das disfunções sexuais. E também necessário lembrar que não se pode ficar na área da biologia do sexo, porque o sexo, sem deixar de ser um fenômeno biológico, é também um fenômeno sociológico e psicológico.

Quando se adquire estes conhecimentos, quase sempre se processa também uma mudança de atitudes. O profissional começa a encarar o cliente como um ser livre para escolher suas opções de conduta erótica, uma pessoa com um passado experiencial próprio, com características culturais peculiares que devem ser respeitadas.

Ao se modificar as atitudes, o médico perde aquela visão paternal - de juiz a de dono da verdade - e deixa de tentar moldar os outros pelos parâmetros de sua própria formação, dos seus próprios padrões de comportamentos e de valores. Descobre que as pessoas tém o direito de serem diferentes e que o conceito de comportamento. "normal" e "anormal" é coisa muito relativa.

A felicidade das pessoas deve ser regida pelos ditames da adequação pessoal e interpessoal. Ser feliz é "estar adequado com...". 
Todo indivíduo sexualmente infeliz é aquele que apresenta uma inadequação intra e/ou interpessoal. Quem está satisfeito com sua conduta erótica e com o comportamento de seu parceiro é feliz e, portanto, adequado. Não cabe ao médico interíerir nas opções e alternativas da conduta erótica de seus clientes, mesmo que estes comportamentos não sejam desejáveis ou aceitos para si mesmo. Não cabe ao médico o papel de julgar, mas de aceitar a liberdade sexual dos outros. Que eles desfrutem do sexo como quiserem desfrutar, que tenham a liberdade de conduzir suas vidas como quiserem conduzir. Mas, é preciso, porém, definir os limites da liberdade e os limites do querer.

Quando se busca o prazer sexual não se pode fazê-lo às custas da saúde física ou psíquica, porque não se pode permitir a liberdade para prejudicar a saúde ou destruir a vida. Neste caso, o médico não pode compactuar com aqueles que ultrapassam este limite ético. Por outro lado, como um bem social, a prática da sexualidade também não pode ferir a sociedade, suas leis e suas normas. É preciso adquirir-se a sabedoria de compatibilizar o uso da sexualidade com o da liberdade responsável. ,

Mas, ao lado da felicidade, vale também falar sobre a infelicidade sexual. Apenas as pessoas inadequadas se queixam. E aqui estou me referindo não só à queixa sexual expressa, mas também àquela forma de infelicidade erótica que pode se, manifestar através de perturbações psicossomáticas.

A educação sexual no consultório tem como pano de fundo a solidez do conhecimento e a elasticidade das atitudes. Não se pede ao profissional da saúde que seja necessariamente um especialista em terapia sexual, mas de todos é exigido o papel de educador.

Educação não é apenas informações sobre aspectos sexuais e reprodutivos. A informação embasa o técnico, mas não forma o educador. Para que esta formação se complete, é necessário que o médico, o psicólogo, o enfermeiro se reformulem atitudinalmente. Que cada um deles examine seus próprios sentimentos em relação à sexualidade; que cada um procure, através do treinamento, ficar à vontade com o que terá de ouvir e com o que terá de falar; que cada um aprenda a não ver o comportamento sexual das pessoas com as lentes de seus óculos culturais. Estas lentes foram lapidadas pela vivência de cada um, dentro de uma escala de valores que, de certa forma, dá sentido à vida pessoal do profissional, mas que é demasiadamente particular para ser aplicada a todas as pessoas e em todas as circunstâncias.

O compromisso do profissional da saúde é com a felicidade pessoal de seus clientes e, para isto, ele deve ser um catalisador a ori- 
entar o processo educativo dos que o procuram. O cliente é que deve escolher o seu caminho e traçar o seu destino.

Comecei esta análise com uma digressão histórica para reforçar a importância da educação sexual. Espero que me permitam agora tirar os olhos do passado e do presente para enxergar o futuro. Pelo menos o futuro que, no meu sonho, eu desejaria ver e viver.

Neste futuro ideal, vejo a comunidade de saúde como era vista pelos olhos amendoados das crianças dos amigos povos chineses.

No meu sonho, tenho certeza que um dia a história repetirá a singeleza oriental. E, qualquer que seja a tecnologia do futuro, a visão profilática predominará sobre a ação curativa. No campo específico da sexualidade, a educação sexual substituirá, lentamente, a necessidade da terapia.

Quando o médico do futuro tiver alcançado a profunda sabedoria dos seus primitivos colegas chineses, cobertos pelo pó dos séculos, quando a história se reescrever, então se compreenderá que o médico, finalmente, conquistou o lugar de cúmplice do criador no processo da criação. Dele se dirá que atingiu a profunda sabedoria de que falava uma estranha e distante civilização oriental, porque finalmente ele deixou de ser apenas um curador de doenças para se transformar num promotor de saúde. 